\title{
USING MONTE CARLO FOR THE ASSESSMENT OF A BROKERED BANK DEPOSIT BUSINESS
}

\author{
Jan Vlachý \\ University of Finance and Administration \\ Estonská 500, 10100 Praha 10, Czech Republic \\ E-mail: jan@vlachy.cz
}

\begin{abstract}
This paper addresses the issue of a cost-benefit analysis when considering the use of third-party distribution channels for saving accounts. Whilst static budgeting methods seem to be generally appropriate for conventional banking projects based on branching or internet, they provide grossly misleading estimates of commissioning expenses, which can lead to completely unrealistic project assessment and poorly designed commission schedules. Using a case study based on actual project experience in the Czech Republic, the author applies a numerical statistical simulation model serving as a potent tool for strategic decision-making as well as business negotiation.
\end{abstract}

Keywords: consumer banking, distribution channels, agency commissions, statistical simulation

JEL Classification: C53, G21, G30

\section{Introduction}

In the course of the last few years, a number of banks in the Czech Republic have considered opportunities to distribute their retail deposit products, in particular popular interest-bearing saving accounts, primarily or solely by means of independent sales force channels. Several new entrants to the market, namely ING, mBank (a Commerzbank group unit) and AXA Bank, have actually chosen to set up their consumer banking businesses utilizing this approach, sometimes in combination with existing tied insurance agents (ING, AXA), supplemented with internet sales and banking facilities (ING), or rudimentary branch and kiosk coverage (mBank).

Various arguments have served to substantiate such proposals. Sales forces ranging from large nationwide organized networks to local outfits and individual operators do exist and have been successfully selling financial services products in the country over the last twenty years, comprising of an essential distribution vehicle primarily for insurance and pension fund policies as well as construction savings and residential mortgages. At the time the project has been developed, the two existing industry associations, AFIZ and USF, jointly representing 29 nontied networks as well as over 1,000 individual members, have published 
an aggregate of the sales figures of 2011 (Table 1) suggesting that their combined memberships have negotiated over 960 thousand contracts.

A historically determined high level of concentration (CNB, 2010) in Czech retail banking has also generally obliged late entrants and aspiring competitors to consider particular innovation strategies, such as specialization, cross-selling or co-branding. At the same time, some of the major networks (Partners for Life Planning, AWD) clearly aspired to become branded financial services providers under their advisory mandates, resulting in a strong appetite to expand their product portfolios.

Last but not least, outsourcing distribution might be perceived as a tool designed to reduce operating leverage of a business project (Helfert, 2001). The substantial fixed costs of branching or establishing dedicated in-house sales forces could thus be avoided, mitigating aggregate business risk.

Table 1 Aggregate Sales Results of 2011 by Non-Tied Sales Forces

\begin{tabular}{lcc}
\hline & \# of Contracts & $\begin{array}{c}\text { Sales Volume [CZK } \\
\text { mil.] }\end{array}$ \\
\hline Insurance & & 4,992 \\
\hline Life Policies & 340,317 & 1,045 \\
\hline Non-Life Policies & 280,444 & \\
\hline Investments and Deposits & 138,915 & 4,731 \\
\hline Mutual Funds and Securities & 121,390 & 929 \\
\hline Pension Funds & 41,248 & 10,303 \\
\hline Construction Savings & 17,441 & $\mathrm{~N} / \mathrm{A}$ \\
\hline Saving Accounts & & 2,286 \\
\hline Lending & 7,971 & 29,116 \\
\hline Construction Loans & 18,278 & \\
\hline Residential Mortgages & & \\
\hline
\end{tabular}

Source: AFIZ (2012), USF (2012)

\section{Conventional Project Description and Analysis}

The following situation, relatively simple, but realistic, will be examined. A commercial bank considers initiation of a retail saving account business as an independent stand-alone project. Market research indicates that the bank has 
potential to gradually attract up to 200 thousand accounts with the average initial balance amounting to 50 thousand crowns (CZK) ${ }^{1}$.

Financial projections have to be made over several years, and it is thus necessary to define the number of accounts $A_{t}$ and their average balance $B_{t}$ as functions of time. One may reasonably choose the exponential function

$$
A_{t}=A\left(1-e^{-\alpha_{t}}\right)
$$

converging towards the target number of accounts $A$ at the rate $\alpha$, with the initial average balance $B_{0}$ growing at the rate $\beta$ according to

$$
B_{t}=B_{0} e^{-\beta_{t}}
$$

A quarterly break-down of the bank's business plan over eight years, based on assumptions of $A=200,000 ; B_{0}=\mathrm{CZK} 50,000 ; \alpha=0.4 ; \beta=8 \%$ would then imply a development of total deposits as indicated under Table 2.

Table 2 Total Deposits Projection (Conventional)

\begin{tabular}{lccccccc}
\hline $\boldsymbol{i}$ & $\mathbf{0}$ & $\mathbf{1}$ & $\mathbf{2}$ & $\mathbf{3}$ & $\mathbf{4}$ & $\mathbf{5}$ & $\mathbf{6}$ \\
\hline$t[\mathrm{yrs}]$ & 0.00 & 0.25 & 0.50 & 0.75 & 1.00 & 1.25 & 1.50 \\
\hline$D_{\mathbf{i}}[\mathrm{CZK}$ mil. $]$ & 0 & 971 & 1,887 & 2,752 & 3,571 & 4,349 & 5,087 \\
\hline $\boldsymbol{i}$ & $\mathbf{7}$ & $\mathbf{8}$ & $\mathbf{9}$ & $\mathbf{1 0}$ & $\mathbf{1 1}$ & $\mathbf{1 2}$ & $\mathbf{1 3}$ \\
\hline$t[\mathrm{yrs}]$ & 1.75 & 2.00 & 2.25 & 2.50 & 2.75 & 3.00 & 3.25 \\
\hline$D_{\mathbf{i}}[\mathrm{CZK}$ mil. $]$ & 5,791 & 6,462 & 7,105 & 7,721 & 8,313 & 8,884 & 9,435 \\
\hline $\boldsymbol{i}$ & $\mathbf{1 4}$ & $\mathbf{1 5}$ & $\mathbf{1 6}$ & $\mathbf{1 7}$ & $\mathbf{1 8}$ & $\mathbf{1 9}$ & $\mathbf{2 0}$ \\
\hline$t[\mathrm{yrs}]$ & 3.50 & 3.75 & 4.00 & 4.25 & 4.50 & 4.75 & 5.00 \\
\hline$D_{\mathbf{i}}[\mathrm{CZK}$ mil. $]$ & 9,969 & 10,487 & 10,991 & 11,483 & 11,964 & 12,436 & 12,899 \\
\hline $\boldsymbol{i}$ & $\mathbf{2 1}$ & $\mathbf{2 2}$ & $\mathbf{2 3}$ & $\mathbf{2 4}$ & $\mathbf{2 5}$ & $\mathbf{2 6}$ & $\mathbf{2 7}$ \\
\hline$t[\mathrm{yrs}]$ & 5.25 & 5.50 & 5.75 & 6.00 & 6.25 & 6.50 & 6.75 \\
\hline$D_{\mathbf{i}}[\mathrm{CZK}$ mil. $]$ & 13,356 & 13,807 & 14,253 & 14,695 & 15,134 & 15,571 & 16,007 \\
\hline $\boldsymbol{i}$ & $\mathbf{2 8}$ & $\mathbf{2 9}$ & $\mathbf{3 0}$ & $\mathbf{3 1}$ & $\mathbf{3 2}$ & & \\
\hline$t[\mathrm{yrs}]$ & 7.00 & 7.25 & 7.50 & 7.75 & 8.00 & & \\
\hline$D_{\mathbf{i}}[\mathrm{CZK}$ mil. $]$ & 16,442 & 16,878 & 17,314 & 17,752 & 18,192 & & \\
\hline & \multicolumn{7}{c}{ Source: Author }
\end{tabular}

A pro-forma budget of such a business can then be set up using customary costvolume-profit analysis, with some rudimentary elements of the activity-based costing approach (Drury, 2004, Soin and Scheytt, 2008).

1 To facilitate international comparison, note that the average exchange rate for euro in 2011 was CZK 24.59, and for the U.S. dollar CZK 17.69 (CNB, 2012). 
We estimate ${ }^{2}$ a constant annual interest margin of $\mu=1.25 \%$ p.a., fixed overheads of CZK 50 mil./yr., and annual direct costs $\chi=0.50 \%$ of total deposits, requiring an initial investment of CZK 30 mil. for the conventional (branching) strategy. Using a discount rate of $10 \%$, it is easy to show that the project has a net present value $N P V=C Z K 87.7$ mil. over the eight-year horizon, assuming null terminal value. It is expected to achieve operating profitability in 2.1 years and (non-discounted) break-even in 4.8 years.

Using total deposits as the key value driver, numerical simulation suggests a linear relationship between percentage changes in NPV and $D$ with sensitivity $\triangle N P V / \triangle D=4.4$ (i.e. a $1 \%$ decrease in $D$ results in a $4.4 \%$ decrease in $N P V$ ). A break-even would thus be reached upon a comprehensive $22.5 \%$ drop in projected $D$.

The conclusions from such an analysis are straightforward. The project is deemed to be acceptable based on the positive NPV criterion, provided sales targets are met. Admittedly, there does exist a residual interest margin risk (with the breakeven interest margin being $1.08 \%$ p.a.), which requires consideration in terms of pricing strategy and competition benchmarking, but this can just serve as a further argument for a sales- and marketing-driven approach with finance essentially playing a supplementary technical role for decision-making.

\section{Third-Party Distribution Project Analysis}

Distribution through third parties (agents) diminishes the project's leverage, and thus business risk, by reducing the required initial investment and overheads (Brigham and Ehrhardt, 2009). Instead, commissions are paid based on actual sales performance and part of the business risk is thus borne by the third parties. However, such an arrangement induces an agency situation (Eisenhardt, 1989) as well as particular factor sensitivities, which may bring about some unintended consequences.

Ideally, the bank's and agent's commercial interests would be coupled by deriving the commissioning schedule from the product's value driver, i.e. current deposits. Thus, at the end of every year, the average balance on an account would be calculated and the bank would pay the responsible agent a fixed percentage therefrom. Commission expenses would become prevailing direct costs.

Let us assume that when using third-party distribution, overheads would drop to just CZK 10 mil./yr., i.e. by $80 \%$, the remaining assumptions/parameters including the initial investment remaining unchanged. Retaining the NPV

\footnotetext{
2 All estimates have been based on calibrated Delphi panel evaluations and budgetary assumptions.
} 
of the branching strategy allows for total annual direct costs of .77\%, which means that the bank would be in a position to offer its agents commissions up to $0.27 \%$ of current deposits. Thus, the bank would still project NPV $=$ CZK 87.7 mil., but with substantially less risk, as indicated by the sales sensitivity of this arrangement of just $\triangle N P V / \Delta D=2.5$, and its break-even point at $-40.1 \%$ of sales.

Unfortunately, such a commissioning schedule is not viable, in practice. Besides legal issues (due to banking secrecy, a third party cannot possibly obtain unmitigated access to clients' account balances which is necessary to properly reconcile the commissions claim), it would not be commensurate with generally accepted industry practice, derived primarily from insurance sales, representing most agents' primary source of income and conforming to their, rather myopical, mode of operation, as well as to the needs of the multilevel structure characteristics for major networks.

It would simply not be worth the effort for most agents to acquire a banking client and, if the average account balance actually added up to CZK 50,000, for example, receive CZK 135 (i.e. €5.40) in a year's time, even if there were an upside potential from the long-term relationship perspective.

In fact, the bank is only in a position to negotiate schedules comprising of a flat commission (i.e. a finder's fee paid to the agent upon the opening of an account), a volume-based commission (i.e. a performance fee based on the deposit increment), or some combination of both.

A severe inconvenience concerning such an arrangement, however, stems from the fact that neither of these cost drivers translates directly into the total deposit value driver. It is therefore grossly misleading to use conventional-style budgeting for its analysis.

For example, the bank might conclude that, under a flat-fee only system, it would pay total quarterly commissions amounting to the projected increase in the number of accounts multiplied by the flat fee rate, i.e. budget its total commission costs as

$$
\tau_{i}=\left(A_{i}-A_{i-1}\right) \Pi
$$

This suggests a capacity to pay commissions of up to $\pi=\mathrm{CZK} 1,400$ per account, again using the $N P V=C Z K 87.7$ mil. benchmark. Such a figure actually seems fairly competitive even when compared to commissions of products, which are generally much more profitable from the financial institutions' point of view. However, such a reasoning is fundamentally flawed.

In particular, the net increment in the number of accounts includes account closings. More accounts have to be opened, and paid for, than expected, which is 
a factor gaining significance in later years. Making the same point from a different perspective, it seems rather unrealistic to run a sustainable business that would spend CZK 27 mil. on commissions in the first quarter, CZK 4 mil. in the $20^{\text {th }}$ quarter and just over CZK 1 mil. in 8 years' time.

Similarly, if the bank were to choose a schedule based purely on net incremental deposits, its calculation could be based on

$$
\Gamma_{i}=\left(D_{i}-D_{i-1}\right) \pi
$$

seemingly allowing for performance fee rates up to $\pi=1.66 \%$. Again, such an intuitive approach would be incorrect, due to the volatility of saving accounts. Sooner or later, the balance on any account is due to decrease and it is unrealistic to assume that agents would readily refund the bank on the base of "negative balance increments."

Let us further illustrate the issue using a combined schedule of $\Pi=$ CZK 300 , and $\pi=0.2 \%$, and the average anticipated balance of CZK 50,000 deposited with the bank over the account's life.

A naïve calculation would assume that total commissioning costs on that particular account of CZK 400, consisting of a CZK 300 flat fee and CZK 50,000 $\times$ $0.2 \%=$ CZK 100 acquisition fee. In reality, however, the actual account balance might develop e.g. as under Figure 1 (thick line, rather than the dashed line). Even though the average balance, i.e. source of revenue for the bank, remains unchanged, the actual commission payments (columns) would total up to CZK 610 when adding up all the pertaining (e.g. quarterly) billing periods.

Figure 1 Impact of Account Volatility on Commission Costs

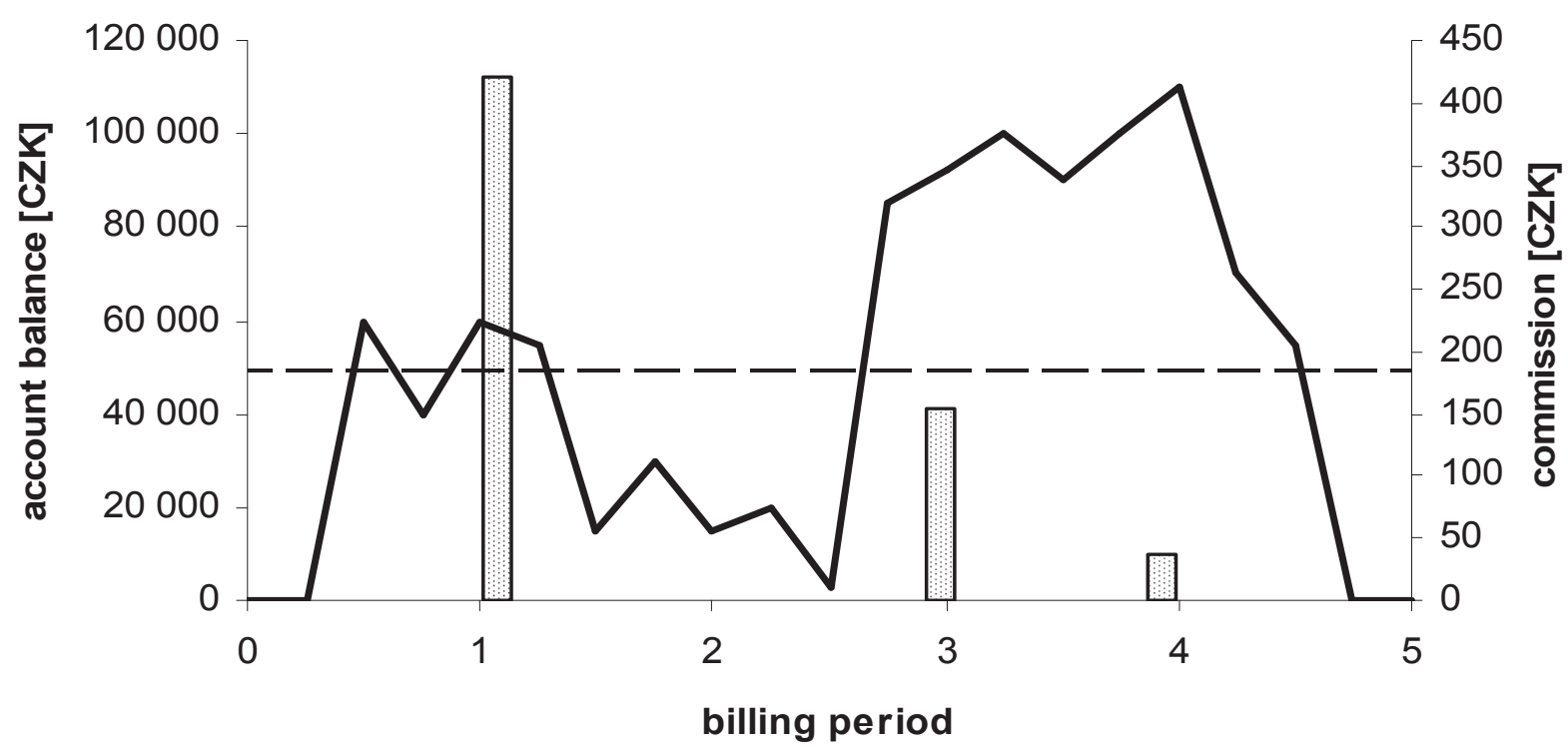

Source: Author 
The essential weakness of the conventional budgeting approach thus stems from the fact that saving accounts tend to behave erratically, which strongly understates the budget whenever conventional, i.e. static, analytical methods are used.

\section{Statistical Modeling of Distribution Costs}

The impacts of commissioning schedules on costs and performance can, however, be studied and quantified using a particular application of statistical (Monte Carlo) simulation (Mun, 2006, Charnes, 2007).

A relatively straightforward model has been set up to perform up to $A$ simulation runs, commensurate with the target number of accounts. In the present case, with $A=200,000$, this ensures reasonable accuracy of the NPV estimate (in case projected A were substantially lower, sequential simulation series would be run), as well as processing times when using specialized simulation software.

Each simulation run represents the behavior of a single account maintained with the bank over 32 quarterly periods. For the sake of process optimization, the same account can technically be used by different clients, upon former clients' account closings. However, distinct clients' behavior remains completely independent even when posted in the same account.

Under this general model framework, any client's behavior is defined by three random processes characterizing the initial account balance (deposit), development of that balance over time, and the account-closing event.

Accounts come into being so that their total number at the end of each period $t$ fits the function $A_{t}=A\left(1-e^{-\alpha_{t}}\right)$. This value thus grows asymptotically, in accord with the assumption of the business plan (obviously, even the uncertainty in its parameters could be easily embraced by simulation, but would bring too much ambiguity into the model and its interpretation).

The initial deposit is characterized as a random value with mean $B_{t}$ and standard deviation $\sigma_{B}$ under log-normal distribution, to ensure that the initial deposit always turns positive. Again, $B_{t}=B_{0} e^{-\beta_{t}}$, as stipulated by the original business plan.

Intertemporal balance changes on any given account $\mathrm{d} b i$ (until termination) are described as a geometric Brownian motion, defined by a stochastic differential function, where $d w$ is generated as a Gaussian random. The current balance thus always depends on the previous balance, a trend parameter $\beta$, and volatility $\sigma$ according to the function

$$
\frac{d b_{i}}{b_{i}}=\beta d t+\sigma d w
$$


Finally, account closings are characterised as a Poisson process event, where the probability of closing an account within a period $\Delta T$ from its opening equals

$$
P(z)=\omega e^{-\omega \Delta T}
$$

The point of time when any particular account will be closed can then be determined using a standardised uniformly distributed random number $U$ using the inverted function

$$
T=-\ln U / \omega
$$

The impact of the account volatility factors, using parameters summarily listed under Table 3, can now be clearly illustrated and compared to the results of the static budgeting approach, assuming that a commissioning schedule combining $\Pi=$ CZK 300 and $\pi=0.2 \%$ is being considered.

Table 3 Functional and Stochastic Parameters of the Simulation

\begin{tabular}{lc}
\hline$A$ & 200,000 \\
\hline$\alpha$ & 0.4 \\
\hline$\sigma$ & $50 \%$ \\
\hline$\omega$ & 0.4
\end{tabular}

\begin{tabular}{lc}
\hline$B_{0}$ & CZK 50,000 \\
\hline$\beta$ & $8 \%$ \\
\hline$\sigma_{B}$ & CZK 30,000 \\
\hline
\end{tabular}

Source: Author

Conventional budgeting, as described earlier, suggests a NPV $=$ CZK 232.5 million, operating profitability in 1.2 years and break-even in just 3 years, which is clearly superior to the alternative branching strategy. Knowing that this is probably overstating the case for third-party distribution, as discussed earlier, we shall now perform the statistical simulation. Its impacts are dramatic, with a projected NPV* $=$ CZK 85.5 million, which not only diminishes the project's perceived value by $2 / 3$, but actually makes it less valuable than even branching, as summarized under Table 4.

Table 4 Project Assessment Variants

\begin{tabular}{llll}
\hline \multicolumn{1}{c}{ Distribution } & \multicolumn{1}{c}{ Calculation } & NPV & Oper. Profit. \\
\hline Branches & Conventional & CZK 85.5 mil. & 1.9 yrs \\
\hline Third-Party & Conventional & CZK 232.5 mil. & 1.2 yrs \\
\cline { 2 - 4 } & Simulation & CZK 87.7 mil. & 2.1 yrs \\
\hline
\end{tabular}

Source: Author

Table 5 compares the development of total commission payments as projected under the two methods for third-party distribution. 
$\Gamma_{\mathrm{i}}$ while using the unrealistic conventional approach tends to decline over time as business saturates, the simulated $\Gamma_{\mathrm{i}}^{*}$ actually grows due to account closings and volatility on a higher base number of accounts.

Table 5 Commissioning Costs Projections

\begin{tabular}{|c|c|c|c|c|c|c|c|}
\hline$i$ & 0 & 1 & 2 & 3 & 4 & 5 & 6 \\
\hline$\Gamma_{\mathrm{i}}[\mathrm{CZK}$ mil. $]$ & 0 & 7.65 & 7.00 & 6.41 & 5.87 & 5.38 & 4.94 \\
\hline$\Gamma_{\mathrm{i}}^{*}[\mathrm{CZK}$ mil. $]$ & 0 & 7.66 & 7.90 & 8.10 & 8.33 & 8.55 & 8.71 \\
\hline$i$ & 7 & 8 & 9 & 10 & 11 & 12 & 13 \\
\hline$\Gamma_{\mathrm{i}}[\mathrm{CZK}$ mil. $]$ & 4.54 & 4.18 & 3.85 & 3.55 & 3.28 & 3.04 & 2.82 \\
\hline$\Gamma_{\mathrm{i}}^{*}[\mathrm{CZK}$ mil. $]$ & 8.94 & 9.15 & 9.35 & 9.47 & 9.50 & 9.78 & 9.86 \\
\hline$i$ & 14 & 15 & 16 & 17 & 18 & 19 & 20 \\
\hline$\Gamma_{\mathrm{i}}[\mathrm{CZK}$ mil. $]$ & 2.62 & 2.44 & 2.28 & 2.14 & 2.01 & 1.89 & 1.78 \\
\hline$\Gamma_{\mathrm{I}} *[\mathrm{CZK}$ mil. $]$ & 10.08 & 10.17 & 10.46 & 10.53 & 10.70 & 10.86 & 11.05 \\
\hline$i$ & 21 & 22 & 23 & 24 & 25 & 26 & 27 \\
\hline$\Gamma_{\mathrm{i}}[\mathrm{CZK}$ mil. $]$ & 1.69 & 1.60 & 1.52 & 1.46 & 1.40 & 1.34 & 1.30 \\
\hline$\Gamma_{\mathrm{i}}^{*}[\mathrm{CZK}$ mil. $]$ & 11.19 & 11.24 & 11.48 & 11.66 & 11.75 & 11.81 & 11.95 \\
\hline$i$ & 28 & 29 & 30 & 31 & 32 & & \\
\hline$\Gamma_{\mathrm{i}}[\mathrm{CZK}$ mil. $]$ & 1.25 & 1.22 & 1.19 & 1.16 & 1.14 & & \\
\hline$\Gamma_{\mathrm{i}}^{*}[\mathrm{CZK}$ mil. $]$ & 12.19 & 12.41 & 12.54 & 12.54 & 12.82 & & \\
\hline
\end{tabular}

Source: Author

\section{Concluding Remarks}

In this paper, we have used statistical simulation to solve a budgeting problem encountered by a bank, which intends to outsource its deposit-sourcing business. The resulting figures and, most notably, contradictory decision-making outcomes, clearly illustrate the inadequacy of conventional costing approaches and indicate the necessity of innovative solutions. At the same time, we have shown Monte Carlo to be a perfectly viable tool for managerial support in the budgeting process.

Even though several contentious issues may arise with the statistical simulation model, basing their merits primarily on parameterization assumptions and a lack of feedback, it does clearly outperform any form of conventional static analysis due to its addressing the dynamics of the underlying processes. In practice, it may serve to facilitate a quantitative comparison of various commission schedules, their sensitivity towards particular assumptions, as well as to analyze the impacts of potentially effective and negotiable commercial measures such as counterparty segmentation, account-pool based commissioning or variants of deferred remuneration. 


\section{References}

AFIZ (2012). Asociace finančních zprostředkovatelů a finančních poradců České republiky. Available from: http://www.afiz.cz, accessed 10 December 2012.

Brigham, E. F. - Ehrhardt, M. C. (2009). Financial Management: Theory and Practice, South-Western. ISBN 978-1439078099.

Charnes, J. (2007). Financial Modeling with Crystal Ball and Excel, John Wiley. ISBN 978-1118175446.

CNB (2010). Czech National Bank. http://www.cnb.cz, accessed 15 September 2010.

Drury, C. (2004). Management and Cost Accounting, Thomson. ISBN 9781844805662.

Eisenhardt, K. M. (1989). Agency Theory: An Assessment and Review, Academy of Management Review, 14(1), pp. 57-74.

Helfert, E. A. (2001). Financial Analysis: Tools and Techniques, McGraw-Hill. ISBN 978-0071378345.

Mun, J. C. (2006). Modeling Risk: Applying Monte Carlo Simulation, Real Options Analysis, Forecasting and Optimization Techniques, John Wiley. ISBN 9780471478850.

Plhoň, T. (2010). Češi mají spořící účty v oblibě i přes pokles úroků. Ekonom, 4 August.

USF (2010). Unie společností finančního zprostředkování a poradenství. http://www.usfcr.cz, accessed 10 December 2012.

Soin, K. and Scheytt, T. (2008). Management Accounting in Financial Services. In: Chapman, C. S. - Hopwood, A. G. - Shields, M. D. (eds.) Handbook of Management Accounting Research, 3, Elsevier, pp. 1385-1395. ISBN 9780080879291 